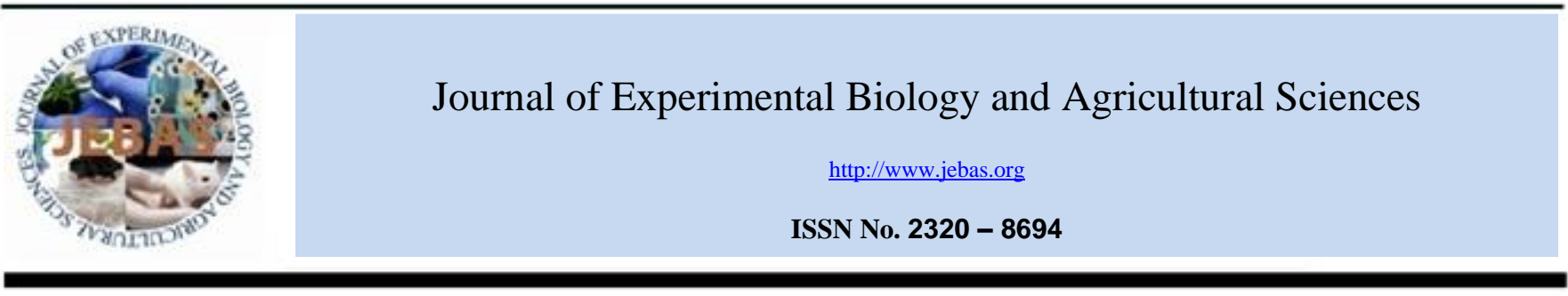

\title{
MESQUITE (Prosopis juliflora DC.) HAS STIMULATORY EFFECT ON NITRATE REDUCTASE ACTIVITY IN RICE SEEDLINGS
}

\section{Gowsiya Shaik ${ }^{1}$ and Santosh Kumar Mehar ${ }^{1,2, *}$}

${ }^{1}$ Department of Botany, Sri Venkateswara University, Tirupati, AP, India

${ }^{2}$ Dept. of Botany, J.N.V. University, Jodhpur, India

Received - October 19, 2015; Revision - November 08, 2015; Accepted - January 31, 2016

Available Online - February 20, 2016

DOI: http://dx.doi.org/10.18006/2015.4(1).47.51

KEYWORDS
Prosopis juliflora
Aqueous leaf extract
Rice
Nitrate reductase

\begin{abstract}
Prosopis juliflora is an invasive and allelopathic plant widespread in most parts of the world. P. juliflora is known to influence the growth of plants growing in its vicinity by the release of the allelochemicals during the decomposition of its litter. The negative effect is manifested by inhibition of the various physiological processes of the target plants. In the present study the effect of aqueous leaf extract of $P$. juliflora on the nitrogen metabolism of rice seedlings was assessed through the means of estimation of nitrate reductase (NR) activity of rice seedlings. For the study, aqueous leaf extract of dry mature leaves was prepared. From this, three concentrations viz., $1 \%, 10 \%$, and $25 \%$ of the leaf extract were prepared by diluting with distilled water, while distilled water served as control. Rice seeds were incubated in different concentrations of extract for 10 days. Germination data was recorded and used for calculating the germination indices. After 10 days of exposure to the extract, seedlings were harvested and measurements for root and shoot length, fresh weights of root, shoot, and seed was taken and nitrate reductase activity of the seedlings was assayed. Germination and phenotypic results showed no negative affect by the extract. The activity of NR significantly increased with increase in the concentration of the extract. Our study revealed that the activity of NR was promoted by the extract addition.
\end{abstract}

* Corresponding author

E-mail: santoshkumar.1@rediffmail.com (Santosh Kumar Mehar)

Peer review under responsibility of Journal of Experimental Biology and Agricultural Sciences.

Production and Hosting by Horizon Publisher (http://publisher.jebas.org/index.html).

All rights reserved.
All the article published by Journal of Experimental Biology and Agricultural Sciences is licensed under a Creative Commons Attribution-NonCommercial 4.0 International License Based on a work at www.jebas.org.

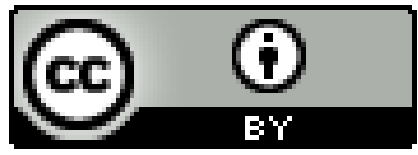




\section{Introduction}

The word Allelopathy was coined by Plant Physiologist Mollisch (1937). The word Allelopathy (allelon + pathos) is derived from the Greek allelon, 'of each other', and pathos, 'to suffer'; hence it means: the injurious effect of one upon another. The term thus relates the scientific knowledge which concerns the production of biomolecules by one plant, mostly secondary metabolites, that can induce suffering in, or give benefit to, another plant. It therefore involves the biochemical interaction among plants. A plant influencing other plants growing in its vicinity, by the release of chemicals in the rhizosphere or through the litter, is known as allelopathic. The formal definition for the allelopathy is "any direct or indirect harmful or beneficial effect by one plant (including microorganisms) on the other, through production of chemical compounds that escape into the environment" (Mollisch, 1937; Rizvi \& Rizvi, 1992). There are hundreds of plants which were reported to be allelopathic in nature (Mollisch, 1937; Sen \& Chawan, 1970; Rizvi \& Rizvi, 1992; Thoyabet et al., 2009; Weston \& Duke, 2003). The chemicals that are released from the allelopathic plant are known as allelochemicals. Allelochemicals in majority are secondary metabolites, released into the environment as exudates, volatiles and/or residues of plant tissue decomposition (Weston \& Duke, 2003). These allelochemicals when released into the environment have been shown to possess a broad activity spectrum on biological systems in surroundings (Corcuera et al., 1993; Wink et al., 1998). The effects of allelochemicals' action has been detected and reported at different levels of plant viz., molecular, structural, biochemical, physiological and ecological levels (Gniazdowska \& Bogatek, 2005).

Prosopis juliflora is reported to influence the growth of other plants (Rizvi \& Rizvi, 1992; Thoyabet et al., 2009). Phenolic compounds present in this plant have biological toxicity towards many plants and can cause disturbances in various processes by interfering with the enzymology of the target plants. Our previous works on germination and seedling growth of rice by the $P$. juliflora extracts has showed no negative influence at lower concentrations, instead the effects were stimulatory (Mehar, 2011; Shaik \& Mehar, 2014; Shaik $\&$ Mehar, 2015). In the present investigation, the effect of $P$. juliflora on the nitrogen metabolism of rice plants was analyzed by assessment of variation in the activity of NR when the rice seedlings are exposed to $P$. juliflora litter extract.

\section{Materials and methods}

\subsection{General methodology}

Karnool Sona variety of rice was used as the test plant in the study. Collection of $P$. juliflora leaf material and processing is detailed in our earlier studies (Shaik \& Mehar, 2014; Shaik \& Mehar, 2015). 2D-DM (2 day dry mature) leaves' extract of $P$. juliflora was used as source of allelopathic material at three concentrations viz., $1 \%, 10 \%$ and $25 \%$, while distilled water served as control.

\subsection{Setup of the experiment}

Seeds were surface sterilized using $0.1 \% \mathrm{HgCl}_{2}$ for 60 seconds and kept for incubation in the different petriplates containing $10 \mathrm{ml}$ of the above treatments (during the initial wetting of the filter papers). In each petriplate, 10 seeds were placed and the triplicates of the each treatment were maintained. The incubation period was 10 days at the room temperature of $28^{\circ}$ $\mathrm{C} \pm 2$.

\subsection{Data Collection}

Germination data collected throughout the incubation period was used for calculating germination indices i.e. total germination (GT), speed of germination(S), speed of accumulated germination (AS), co-efficient of the rate of germination (CRG) as per Chiapusio et al. (1997). After 10 days of exposure to allelopathic extract, Root length (RL) and Shoot length (SL) were measured.

\subsection{Nitrate reductase assay}

Rice seeds germinated in extracts were used for nitrate reductase assay according to the method of Hageman \& Hucklesby (1971) and Evans \& Nason (1953) after 10 days of exposure to allelopathic extract.

\subsection{Statistical analysis}

All the germination indices' values for all the treatments were compared with control using Mann-Whitney U-Test. RL and SL were compared to control using paired t-test. Activity of nitrate reductase was compared with control using t-test. Mann-Whitney U-Test and T-test were performed using SPSS.

\section{Results}

\subsection{Germination}

Result of study indicated that leaf extract did not show any inhibitory effect on the germination of rice seeds. The Gt, S, AS and CRG were $100 \%$ in $1 \%$ and $10 \%$ extracts but at higher concentration i.e. $25 \%$ some reduction was reported in the Gt, S, AS and CRG and it was $83.3 \%, 66.7 \%, 66.7 \%$ and $71.1 \%$ respectively. All the germination indices were comparable to control at all the concentration (Table 1, values are as percentage of control).

Growth of the plant was not significantly reduced by any of the extract concentrations. SL (Figure 1a) and RL (Figure 1b) were not affected by the exposure to extract. In comparison with control, the change in the root and shoot lengths of the seedling were statistically not significant. 
Table 1 Germination indices values of different treatments (values are the percentage of the control).

\begin{tabular}{|lcccc|}
\hline Treatments & $\mathbf{G t}$ & $\mathbf{S}$ & $\mathbf{A S}$ & $\mathbf{C R G}$ \\
\hline $\mathbf{1 \%}$ & $100^{\mathrm{NS}}$ & $100^{\mathrm{NS}}$ & $100^{\mathrm{NS}}$ & $100^{\mathrm{NS}}$ \\
\hline $\mathbf{1 0 \%}$ & $100^{\mathrm{NS}}$ & $100^{\mathrm{NS}}$ & $100^{\mathrm{NS}}$ & $100^{\mathrm{NS}}$ \\
\hline $\mathbf{2 5 \%}$ & $83.33333^{\mathrm{NS}}$ & $66.66667^{\mathrm{NS}}$ & $66.66667^{\mathrm{NS}}$ & $71.11111^{\mathrm{NS}}$ \\
\hline
\end{tabular}

$\mathrm{Gt}=$ Total germination, $\mathrm{S}=$ Speed of Germination, $\mathrm{AS}=$ Speed of accumulated Germination, $\mathrm{CRG}=\mathrm{Co}$-efficient of the rate of Germination, NS=Not Significant

\subsection{Nitrate Reductase activity}

In the present investigation, NR activity was maximum at $25 \%$ followed by the $10 \%$ and $1 \%$. It was significantly $(\mathrm{p} \leq 0.001)$ promoted in comparison to control. There was linear relationship between the concentration of the extract and the NR activity of rice seedlings $\left(\mathrm{R}^{2}=0.966(\mathrm{y}=0.013 \mathrm{x}+0.039\right.$; Figure 2.). This indicates the extracts have stimulatory affect on the activity of the NR enzyme.

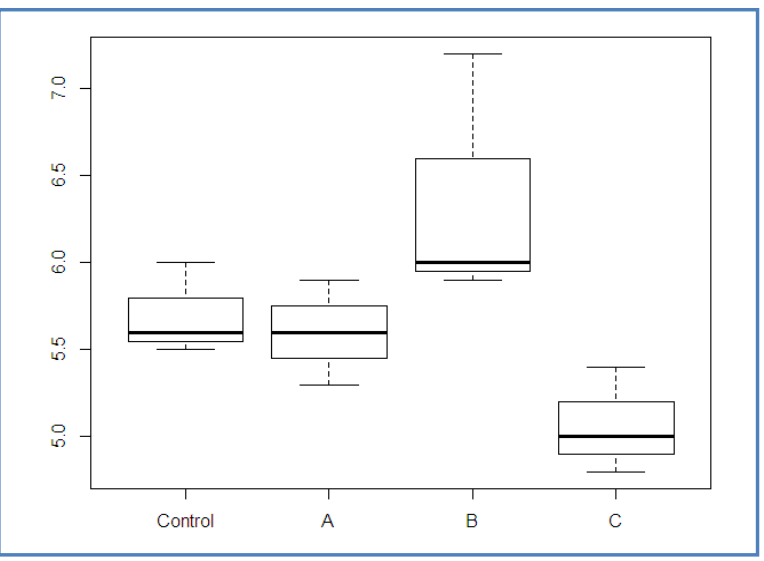

A

\section{Discussion and Conclusions}

Seed germination assays are the preliminary screening to check the effect of allelopathic extracts. In the present study, germination indices clearly indicated that the there is no inhibition of the germination when exposed to the allelopathic extracts of the P. juliflora. Even the higher concentration, 25\% was not inhibitory. Results of present study are in contrast to the reports of Siddique et al. (2009).

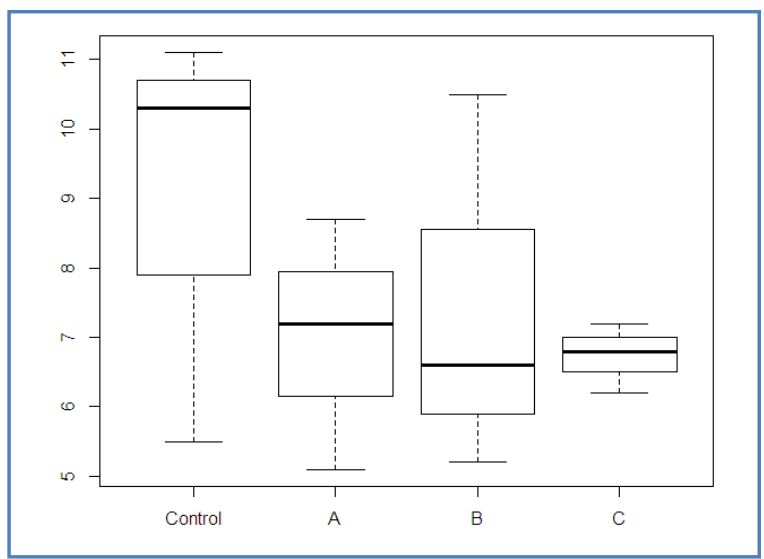

B

Figure 1 Boxplots for shoot length (A) and root length (B), the treatments labeled A, B and C represent $1 \%, 10 \%$ and $25 \%$ of $P$. juliflora extract

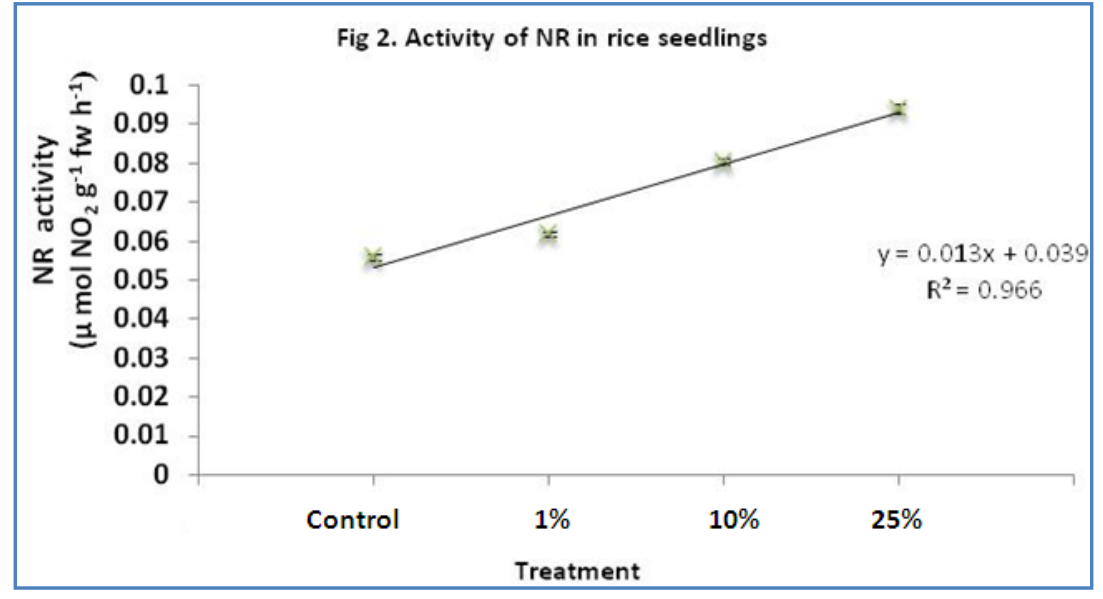

Figure 2 NR activity of Rice seedlings 
Although there are reports of the negative effect of $P$. juliflora extracts on the germination (Noor et al., 1995; Nakano et al., 2001), it also needs to be considered that the effect is dependent on the concentration and type of the material being used. It was reported that, seed characteristics such as seed size and seed coat permeability can influence the uptake and effects of allelochemicals in seeds and interference of the allelochemicals varies accordingly (Marianne et al., 2000).

Seed germination assays (Barnes \& Putnam, 1987; Pérez, 1990; Chase et al., 1991) showed that species with small seeds were more sensitive, and hence were inhibited more than larger seeded species when exposed to similar concentration of the allelochemicals. Seedling parameters also had no significant reduction. In this manner findings of present study are contradictory to the findings of Thoyabet et al. (2009) and Sen\& Chawan (1970). Thoyabet et al. (2009) has reported the reduced root length by the extracts of leaves of $P$. juliflora. Similarly, Sen\& Chawan (1970) reported the inhibition in germination and early seedling growth. As in the case of germination, effect on the seedling parameters is also dependent on the type of donor plant, test plant and the concentration of the extracts being used.

Along with the suppressing effects on the germination and seedling parameters the allelochemicals are reported to suppress the activity of the respiratory and photosynthetic enzymes, and therefore, there is perceived scope for the inactivation of the NR by the allelochemicals.

Nitrogen and sulphur are very important nutrients for plant growth (Fazili et al., 2010) and play important role in amino acid biosynthesis, and regulate the protein synthesis (Harris et al., 2000). According to Fazli et al., (2005), the increased amount of nitrogen and sulphur nutrition affected lipid accumulation, acetyl-CoA concentration and acetyl-CoA carboxylase activity. Nitrate reductase is a key enzyme in the nitrogen metabolism. Nitrate is assimilated through a pathway involving nitrate uptake steps and by two reductive steps catalyzed by the enzymes NR and nitrite reductase (NiR). But, here we have found no inhibitory effect on the NR activity; instead with increase in the concentration of the extracts, the NR activity has been promoted.

Based on the above results, here we conclude that extract had no negative effect on the germination of rice seeds, and its seedling growth. Besides, the activity of nitrate reductase was promoted by the extract addition which further suggests that the addition of litter has stimulatory effect on the nitrogen metabolism in rice and its overall growth.

\section{Conflict of interest}

Authors would hereby like to declare that there is no conflict of interests that could possibly arise.

\section{References}

Barnes JP, Putnam AR (1987) Role of benzoxazinones in allelopathy by rye (Secale cereale L.). Journal of Chemical Ecology 13: 889-906. DOI: 10.1007/BF01020168.

Chase WR, Nair MG, Putnam AR (1991) 2,2'-oxo-1,1'azobenzene: Selective toxicity of rye (Secale cereal L.) allelochemicals to weed and crop species: 11. Journal of Chemical Ecology 17: 9-18. DOI: 10.1007/BF00994418.

Chiapusio G, Sanchez AM, Reigosa MJ, Gonzalez L, Pellissier F (1997) Do germination indices adequately reflect allelochemical effects on the germination process?. Journal of Chemical Ecology 23: 2445-2453. DOI: 10.1023/B:JOEC.0000006658.27633.15.

Corcuera LJ, Argandona VH, Zúniga GE. Allelochemicals in wheat and barley: role in plant-insect interactions. In: Rizvi SJH, Rizvi V (Eds), Allelopathy Basic and applied aspects, Chapman and Hall, London. DOI: 10.1007/978-94-011-23761_9.

Evans HJ, Nason A (1953) Pyridine Nucleotide-Nitrate Reductase from Extracts of Higher Plants. Plant Physiology 28: 233-254. DOI:10.1104/pp.28.2.233.

Fazili IS, Masoodi M, Ahmad S, Jamal A, Khan JS, Abdin MZ (2010) Interactive effect of sulfur and nitrogen on growth and yield attributes of oilseed crops (Brassica campestris L and Eruca sativa Mill) differing in yield potential. Journal of Plant Nutrition 33: 1216-1228. DOI: 10.1080/01904161003765745.

Fazli IS, Abdin MZ, Jamal A, Ahmad S (2005) Interactive effect of sulphur and nitrogen on lipid accumulation, acetylCoA concentration and acetyl-CoA carboxylase activity in developing seeds of oilseed crops (Brassica campestris L. and Eruca sativa Mill.). Plant Science 168: 29-36. DOI: 10.1016/j.plantsci.2004.07.008.

Gniazdowska A, Bogatek R (2005) Allelopathic interaction between plants: Multi site action of allelochemicals. Acta Physiologiae Plantarum 27: 395-408. DOI: 10.1007/s11738005-0017-3.

Hageman RH, Hucklesby DP (1971) Nitrate reductase from higher plants. Methods in Enzymology 23:491-503. DOI: 10.1016/S0076-6879(71)23121-9.

Harris N, Foster JM, Kumar A, Davies HV, Gebhardt C, Wray JL (2000) Two cDNAs representing alleles of the nitrate reductase gene of potato (Solanum tuberosum L. cv. Desiree): sequence analysis, genomic organization and expression. Journal of Experimental Botany 51: 1017-1026. DOI: $10.1093 /$ jexbot/51.347.1017. 
Marianne K, Morten S, Beate S (2000) Ecological effects of allelopathic plants-a review. NERY Technical Report No 315.

Mehar SK (2011) Assessment of effect of Prosopis juliflora litter extract on seed germination and growth of rice. Food Science and Quality Management 2: 9-18.

Mollisch H (1937) Der Eingfluss einer Pflanze aufdie andereAllelopathie. Fischer, Jena.

Nakano H, Fujji Y, Suzuki T, Yamada K, Kosemura SS, Yamakura S, Suzuki T, Hassegawa K (2001) A growth inhibitory substance exuded from freeze-dried mesquite (Prosopis juliflora (Sw) DC) leaves. Plant Growth Regulation 33: 165-168.DOI: 10.1023/A:1017505702039.

Noor M, Salam U, Khan AM (1995) Allelopathic effects of Prosopis juliflora Swartz. Journal of Arid Environment 31: 83-90. DOI:10.1006/jare.1995.0051.

Pérez FJ (1990) Allelopathic effect of hydroxamic acids from cereals on Avena sativa and A. fatua. Phytochemistry 29: 773776. DOI:10.1016/0031-9422(90)80016-A.

Rizvi SJH, Rizvi V (1992). Allelopathy: Basic and applied aspects. Chapman and Hall, London.

Sen DN, Chawan DD (1970) Ecology of desert plant and observation on their seedlings: III: The influence of aqueous extracts of Prosopis juliflora DC on Euphorbia cardifolia Haines. Vegetatio 21: 277-298. DOI: 10.1007/BF02269669.
Shaik G, Mehar SK (2014) Allelopathic potentialities of an invasive tree, Prosopis juliflora on germination and seedling growth of rice under laboratory conditions. International Journal of Current Biotechnology 2: 22-28.

Shaik G, Mehar SK (2015) Evaluating the allelopathic influence of mesquite (Prosopis juliflora DC.) aqueous leaf extract on the germination of rice (Oryza sativa L.) seeds using different germination indices. International Journal of Pharma and Bio Sciences 6: 280-287.

Siddique S, Bhardwaj S, Khan SS, Meghavanshi MK (2009) Allelopathic effect of different concentration of water extract of Prosopis juliflora leaf on seed germination and radicle length of wheat (Triticum aestivum Var-Lak-1). AmericanEurasian Journal of Scientific Research 4: 81-84.

Thoyabet SA, Ray RH, Sven V, George SE (2009) Effects of leaf extract of Zizyphus spina-christi and Prosopis juliflora on each other's seedlings roots. Allelopathy Journal 23: 111-118.

Weston LA, Duke SO (2003) Weed and crop allelopathy. Critical Reviews in Plant Science 22: 367-389. DOI: 10.1080/713610861.

Wink M, Schmeller T, Latz-Bruning B (1998) Modes of action of allelochemical alkaloids: Interaction with neuroreceptors, DNA, and other molecular targets. Journal of Chemical Ecology 24: 1881-1937. DOI: 10.1023/A:1022315802264. 